J. Dairy Sci. 96:2327-2338

http://dx.doi.org/10.3168/jds.2012-6267

(C) American Dairy Science Association ${ }^{\circledR}, 2013$.

\title{
Increased milk protein synthesis in response to exogenous growth hormone is associated with changes in mechanistic (mammalian) target of rapamycin (mTOR)C1-dependent and independent cell signaling
}

\author{
Q. Sciascia, D. Pacheco, and S. A. McCoard ${ }^{1}$ \\ Animal Nutrition Team, Animal Nutrition and Health Group, AgResearch Grasslands, Private Bag 11008, Palmerston North 4442, New Zealand
}

\begin{abstract}
The objective of this study was to determine if increased milk protein synthesis observed in lactating dairy cows treated with growth hormone $(\mathrm{GH})$ was associated with mechanistic (or mammalian) target of rapamycin complex 1 (mTORC1) regulation of downstream factors controlling nucleocytoplasmic export and translation of mRNA. To address this objective, biochemical indices of mammary growth and secretory activity and the abundance and phosphorylation status of mTORC1 pathway factors were measured in mammary tissues harvested from nonpregnant lactating dairy cows $6 \mathrm{~d}$ after treatment with a slow-release formulation of GH or saline ( $\mathrm{n}=4$ /group). Treatment with GH increased mammary parenchymal weight and total protein content and tended to increase ribosome number and cell size, whereas protein synthetic efficiency, capacity, and cell number were unchanged. Cellular abundance of the mTORC1 components mTOR and (phosphorylated) $\mathrm{mTOR}^{\text {Ser2448 }}$ increased, as did complex eukaryotic initiation factor 4E:eukaryotic initiation factor $4 \mathrm{E}$ binding protein 1 (eIF4E:4EBP1), whereas no change was observed for mTORC1-downstream targets $4 \mathrm{EBP} 1,4 \mathrm{EBP} 1^{\mathrm{Ser} 65}, \mathrm{p} 70 / \mathrm{p} 85^{\mathrm{S} 6 \mathrm{~K}}$ and $\mathrm{p} 70^{\mathrm{S} 6 \mathrm{~K}}$ Thre $389 / \mathrm{p} 85^{\mathrm{S} 6 \mathrm{~K}}$ Thre412. Changes in activation were not observed for any of the targets measured. These results indicate that GH treatment influences signaling to mTORC1 but not downstream targets involved in the nucleocytoplasmic export and translation of mRNA. Increased eIF4E:4EBP1 complex formation indicates involvement of the mitogen-activated protein kinase (MAPK) pathway. Abundance of MAPK pathway components eIF4E, eIF4E $\mathrm{E}^{\mathrm{Ser} 209}$, eIF4E:eIF4G complex, MAP kinase-interacting serine/threonine-protein kinase 1 (MKNK1), MKNK1 ${ }^{\text {Thr197202, }}$, and ribosomal protein S6 kinase, 90kDa, polypeptide 1 (RPS6KA1) increased significantly in response to GH, whereas relative activation of the proteins was unchanged. Expres-
\end{abstract}

Received October 14, 2012.

Accepted January 2, 2013.

${ }^{1}$ Corresponding author: sue.mccoard@agresearch.co.nz sion of IGFBP3 and IGFBP5 increased, that of IGF1R decreased, and that of IGF1 remained unchanged in response to GH. PatSearch analysis of the milk caseins $\alpha_{\mathrm{S} 1}$-casein, $\alpha_{\mathrm{S} 2}$-casein, and $\beta$-casein, MAPK signaling target RPS6KA1, and proliferation gene IGFBP3 mRNA indicated that all contained putative eIF4E-sensitivity elements. In response to $\mathrm{GH}$, these genes were all upregulated, suggesting that increased abundance of eIF4E and eIF4 $\mathrm{E}^{\text {Ser209 }}$ plays a role in mediating their nucleocytoplasmic export. We propose that, in response to GH, the IGF1-IGF1R-MAPK signaling cascade regulates eIF4E-mediated nucleocytoplasmic export and translation of mRNA, whereas mTOR controls cell renewal, cell turnover, and rRNA transcription through an alternative signaling cascade.

Key words: lactation, growth hormone, mechanistic (or mammalian) target of rapamycin (mTOR)

\section{INTRODUCTION}

Cellular regulation of protein synthesis is a tightly coordinated system that utilizes common factors located in the cytoplasm and nucleus (Culjkovic et al., 2008). Cytoplasmic factors are widely recognized as regulators of mRNA translation, whereas their nuclear counterparts control the export of specific mRNAs linked to cell survival, proliferation, and growth (Culjkovic et al., 2005). In the ruminant mammary gland, coordination of these factors relies upon a complex endocrine, mitogen, and nutritional signaling cascade that has yet to be fully elucidated (Brisken and O'Malley, 2010). Identifying and understanding the molecular mechanisms that underpin this coordination may provide fundamental knowledge that leads to the development of novel technologies to increase dairy cow lactation performance. A well-established treatment model used to study increased milk protein synthesis by the ruminant mammary gland is growth hormone $(\mathbf{G H})$. The galactopoietic effect of GH has been well investigated; however, cell signaling mechanisms that mediate its action on the mammary gland are not fully understood (McDowell et al., 1987; Capuco et al., 2001). 
Studies with in vitro models suggest that GH may signal directly to mammary epithelial cells via the growth hormone receptor, through pathways linked to protein synthesis and cellular proliferation (Johnson et al., 2010). Mammary explant studies show that GH alone increases cell survival by suppressing expression of the pro-apoptosis gene insulin-like growth factorbinding protein (IGFBP) 5 (Sakamoto et al., 2007). Evidence from in vivo studies postulates that GH can also act indirectly on the mammary gland via stimulation of liver IGF1 secretion or by increasing blood flow and nutrient availability to the gland (Mepham et al., 1984; Davis et al., 1988; Capuco et al., 2001) These physiological stimuli increase epithelial cell proliferation or secretory activity in the lactating mammary gland (Capuco et al., 2001), indicating the involvement of signaling pathways regulating cell turnover and renewal, RNA transcription, and protein synthesis in mediating the effects of $\mathrm{GH}$ on milk production. We have previously reported that treatment with $\mathrm{GH}$ increases plasma IGF1 concentrations, increases ribosomal protein S6 (RPS6) abundance and phosphorylation, and increases eukaryotic initiation factor $4 \mathrm{E}$ (eIF4E) abundance in the mammary gland of lactating dairy cows (Hayashi et al., 2009). Furthermore, Burgos and Cant (2010), using the bovine mammary epithelial cell line MAC-T, showed that IGF1 increases formation of the eIF4E:eukaryotic initiation factor 4G (eIF4G) complex and $\mathrm{p} 70^{\mathrm{S} 6 \mathrm{~K}}$ phosphorylation, and decreases formation of the eIF4E:eukaryotic initiation factor $4 \mathrm{E}$ binding protein 1 (4EBP1) complex. Interestingly, p70 ${ }^{\mathrm{S} 6 \mathrm{~K}}$ phosphorylation and eIF4E:4EBP1 complex formation can be influenced by the mechanistic (or mammalian) target of rapamycin (mTOR) pathway (Gingras et al., 2001; Ruvinsky and Meyuhas, 2006).

The mTOR protein is an evolutionarily conserved serine/threonine kinase that exists in 2 known complexes, mTORC1 and mTORC2. The mTORC1 complex responds to 4 major signals: nutrients, growth factors, energy, and stress to control protein synthesis, cell size, cellular proliferation, and gene expression, whereas mTORC2 responds to nutrients and growth factors to regulate cytoskeleton formation (Jacinto et al., 2004). Activation of mTORC1 signaling elevates protein synthesis by 2 distinct mechanisms that are cytoplasmic and nuclear in origin. Cytoplasmic mTORC1 phosphorylation of $4 \mathrm{EBP} 1^{\mathrm{Ser} 65}$ uncouples it from eIF4E, allowing the formation of the $5^{\prime}$-m7G cap-dependent eIF4E:eIF4G protein synthesis initiation complex (Gingras et al., 2001). Once protein synthesis has begun, mTORC1 regulates the speed of translation by phosphorylating $\mathrm{p} 70^{\mathrm{S} 6 \mathrm{~K}}$, which in turn phosphorylates its downstream target RPS6 (Schmelzle and Hall, 2000). Nuclear signaling by mTORC1 involves the phosphory- lation of MAF1 to increase rRNA transcription and $\mathrm{p} 85^{\mathrm{S} 6 \mathrm{~K}}$ to increase mRNA transport (Kantidakis et al., 2010).

The aim of this study was to determine if the increased milk protein synthesis observed in dairy cows treated with $\mathrm{GH}$ is associated with changes in mTORC1 signaling and downstream factors regulating nucleocytoplasmic export and translation of mRNA.

\section{MATERIALS AND METHODS}

\section{Animals and Treatments}

All procedures involving animals were carried out in compliance with the guidelines of the AgResearch Grasslands Animal Ethics Committee (Palmerston North, New Zealand), in accordance with the 1999 Animal Welfare Act of New Zealand. The trial design and sample collection methodology have been described in detail elsewhere (Hayashi et al., 2009). Briefly, 8 nonpregnant, lactating second-parity Jersey cows (178-200 d postpartum) were housed in separate indoor stalls and fed a diet formulated to exceed requirements for ME, protein, and essential amino acids. Cows were fed and milked twice daily. A single subcutaneous injection of either a slow-release formulation of commercially available GH (500 mg; Lactatropin, Elanco Animal Health, Bryanston, South Africa) or saline ( $\mathrm{n}=4$ /group) was administered. Six days after injection, cows were milked and then euthanized, mammary glands were trimmed (skin, lymph nodes, fat, and teats removed), and parenchymal tissue (alveolar tissue free of large ducts and blood vessels) was collected and snap frozen in liquid nitrogen $\left(-80^{\circ} \mathrm{C}\right)$ within 5 min for subsequent analyses.

\section{Biochemical Indices}

Mammary tissue from each cow was homogenized in TRIzol reagent (Invitrogen, Auckland, New Zealand), and total RNA, DNA, and protein were extracted according to the manufacturer's protocol. Nucleic acids were quantified using a NanoDrop spectrophotometer (ND-1000; Nanodrop Technologies, Wilmington, DE) and protein was quantified using the Bradford assay (Bradford, 1976). Then, DNA, RNA, and protein were used to determine biochemical indices of cell size (protein:DNA ratio), protein synthetic efficiency (protein:RNA ratio), protein synthetic capacity (RNA:DNA ratio), DNA, RNA, protein concentration, and total parenchymal DNA, RNA, and protein contents. Differences between treatment groups were determined using the T-TEST procedure (SAS Inst. Inc., Cary, NC). Differences between means were considered significant at $P \leq 0.05$. 


\section{Quantitative Real-Time PCR}

RNA Extraction and $\boldsymbol{c D N A}$ Synthesis. Total RNA extracted for biochemical indices was purified by use of RNeasy minikits, with on-column DNase I treatment (Qiagen, San Diego, CA) to remove any residual DNA contamination. Purified RNA was quantified using a NanoDrop spectrophotometer (ND-1000; Nanodrop Technologies), and RNA quality assessed by running $1 \mu \mathrm{g}$ on a $1 \%$ nondenaturing agarose gel, stained with SYBR Safe (Invitrogen). Total RNA (500 ng) was reverse transcribed to make cDNA using the SuperScript VILO cDNA Synthesis Kit and the manufacturer's modified protocol of $120 \mathrm{~min}$ at $42^{\circ} \mathrm{C}$ (Invitrogen).

Primer Design. Primers were designed against mRNA sequences from both Bos taurus and Ovis aries using publicly available data at National Center for Biotechnology Information (NCBI; www.ncbi.nlm.nih.gov) and the Commonwealth Scientific and Industrial Research Organisation (CSIRO; www.livestockgenomics. csiro.au/sheep/), using the Roche Universal ProbeLibrary assay design center (www.roche-applied-science. com/sis/rtpcr). Primers for IGF1 had been published previously (Pfaffl et al., 2002a). Primers were made by Integrated DNA Technologies (Antwerp, Belgium) and purified using desalting to remove short truncated products and small organic contaminants. Primer sequences are presented in Table 1.

Quantitative PCR Assay. Quantitative real-time PCR (qPCR) was performed using the SensiFAST SYBR No-ROX Kit (Bioline, London, UK) in a RotorGene 6000 (Qiagen), with the template and all reagents used at half of the manufacturer's recommended volume. The PCR efficiency and quantification cycle values were obtained for each sample using LinRegPCR (Ramakers et al., 2003). Two reference genes, MAPK1 and $S H C 1$, were identified using NormFinder (http:// www.mdl.dk/publicationsnormfinder.htm; Andersen et al., 2004). Reactions were performed in triplicate with all data entered into REST 2009 (http://www.genequantification.de/rest-2009.html; Pfaffl et al., 2002b) and the fold change in expression ratios between the means of 2 treatment groups determined. All qPCR data were reported according to published guidelines (Bustin et al., 2009).

\section{Protein Precipitation and Immunoblotting}

Protein Extraction. Tissue was homogenized in cold protein extraction buffer $(20 \mathrm{~m} M$ Tris- $\mathrm{HCl}, \mathrm{pH}$ 7.4, $1 \mathrm{~m} M$ EDTA, pH 8, $1 \mathrm{~m} M$ ethylene glycol tet-

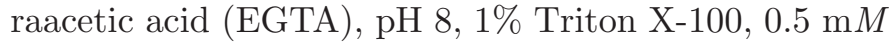
sodium vanadate, $1 \mathrm{~m} M$ benzamidine hydrochloride,

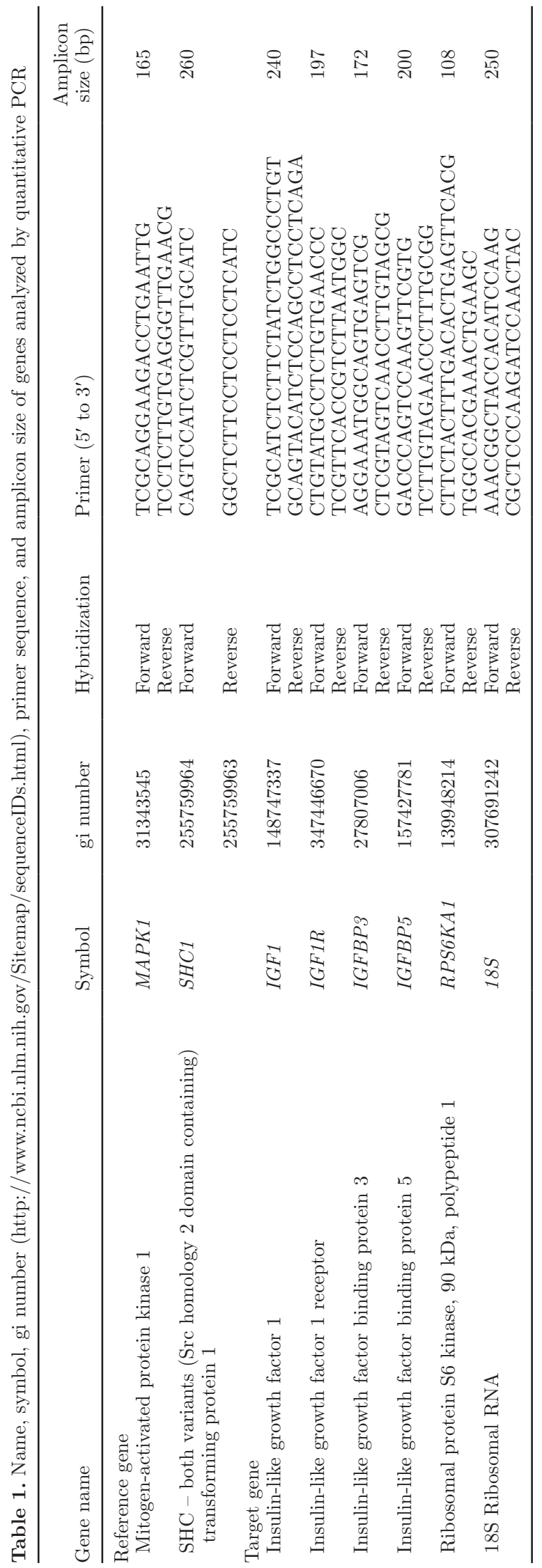

Journal of Dairy Science Vol. 96 No. 4, 2013 
$1 \mathrm{~m} M$ dithiothreitol, $0.1 \mathrm{~m} M$ phenylmethanesulfonyl fluoride, $1 \mu \mathrm{g} / \mathrm{mL}$ pepstatin, $1 \mu \mathrm{g} / \mathrm{mL}$ antipain, $1 \mu \mathrm{g} /$ $\mathrm{mL}$ leupeptin), centrifuged at 4,820 $\times g$ for $10 \mathrm{~min}$ at $4^{\circ} \mathrm{C}$. The supernatant was collected and protein concentration determined using the Bradford assay (Bradford, 1976).

Protein Precipitation. For analysis of eIF4E complex, protein supernatants were treated with 7-methyl guanosine-5'-triphosphate (GTP) sepharose beads following the manufacturer's protocol (GE Healthcare, Auckland, New Zealand). Immunoprecipitation of total mTOR was performed with the primary antibody (Cat. No. 2672, Cell Signaling Technologies, Boston, MA) using the protein G-Dynabead magnetic separation kit and DynaMag-2 magnetic separator according to the manufacturer's protocol (Invitrogen).

SDS-PAGE and Western Blotting. All protein samples were separated via reducing SDS-PAGE. Protein targets mTOR, mTOR ${ }^{\mathrm{Ser} 2448}$, eIF $4 \mathrm{G}, \mathrm{p} 70^{\mathrm{S} 6 \mathrm{~K}} / \mathrm{p}^{2} 5^{\mathrm{S} 6 \mathrm{~K}}$, and $\mathrm{p} 70^{\mathrm{S} 6 \mathrm{~K}}$ Thre389/p85 ${ }^{\mathrm{S} 6 \mathrm{~K}}$ Thre412 (Cat. Nos. 2672, 2971, 2469, 9202, 9205, respectively; Cell Signaling Technologies) were separated on 3 to $8 \%$ Tris-acetate gels (Invitrogen), whereas eIF4E, eIF4E ${ }^{\text {Ser209 }}$, 4EBP1, 4EBP1 ${ }^{\text {Ser65 }}$, RPS6KA1, MKNK1, and MKNK1 $1^{\text {Thr197/202 }}$ (Cat. Nos. 9742, 9741, 9452, 9451, 9333, 2195, 2111, respectively; Cell Signaling Technologies) were separated on a 4 to $12 \%$ Bis-Tris gradient gel (Invitrogen), according to manufacturer's instructions. Proteins were then transferred using an iBlot Gel Transfer Device to a polyvinylidene difluoride membrane (Invitrogen). The membrane was then incubated with primary antibodies, followed by a horseradish peroxidase-conjugated secondary antibody. Proteins were then visualized using SuperSignal West Pico enhanced chemiluminescence reagents (BioRad, Auckland, New Zealand) and Kodak Biomax XAR film (Rochester, NY). At least 3 repeat films were scanned using an HP Photosmart B110 (Hewlett Packard, Auckland, New Zealand) set at $300 \mathrm{dpi}$, and the signal intensity of individual bands was determined by densitometric measurement using ImageJ software (National Institutes of Health, Bethesda, MD). Within each film, individual band intensities were calculated per unit of DNA to express relative abundance per cell. The calculated values were then expressed as a ratio of the total signal from all bands on the film to reduce band intensity variation between repeat films. To determine activation, the intensities of phosphorylated signals were normalized to total protein intensities. Differences between treatment groups were analyzed using the T-TEST procedure (SAS Inst. Inc.). Differences between means were considered significant at $P \leq 0.05$.

\section{Analysis of mRNA 3' Untranslated Region for Putative elF4E Sensitivity Element}

The publicly available Ensembl (www.ensembl.org) bovine database was used to obtain the $3^{\prime}$ untranslated region (UTR) sequences of $\alpha_{\mathrm{S1}}$-casein (gi: 31341348; http://www.ncbi.nlm.nih.gov/Sitemap/sequenceIDs. html), $\alpha_{\mathrm{S} 2}$-casein (gi: 31341749), $\beta$-casein (gi: 31341343),

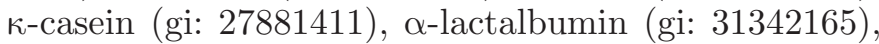
ß-lactoglobulin (gi: 81294269), IGFBP3 (gi: 27807006), IGFBP5 (gi: 157427781), RPS6KA1 (gi: 139948214), and G1/S-specific cyclin-D1 (gi: 114053226). The PatSearch algorithm (http://itbtools.ba.itb.cnr.it/patsearch) was used to identify putative eIF4E-sensitivity elements (4E-SE) corresponding to the conserved sequence element UX2UX2A within the 3' UTR.

\section{RESULTS}

\section{Effect of GH Treatment on Mammary Gland Weight and Biochemical Measures}

Total parenchymal RNA $(33 \%, P=0.10)$ and protein $(34 \%, P=0.06)$ tended to be increased, whereas DNA concentration tended to decrease $(20 \%, P=0.09)$ in GH-treated compared with control cows (Table 2). Cell size tended to be increased by $30 \%(P=0.14)$ in GH-treated cows compared with control cows, whereas total parenchymal DNA content (cell number) did not change with treatment. Mammary parenchymal weight was increased such that GH-treated cows had a $33 \%$ ( $P$ $=0.03$ ) heavier mammary parenchyma compared with control cows. These results indicate greater total ribosome number (protein synthetic capacity), which supports increased mammary parenchymal protein content leading to increased cell size, mammary parenchymal weight, and decreased DNA concentration.

\section{Effect of GH Treatment on the mTORC1 Signaling Pathway}

The mTOR pathway has been identified in mammalian cells to regulate ribosomal RNA transcription (Iadevaia et al., 2012) and mRNA nucleocytoplasmic export and translation (Ma et al., 2008). Treatment with GH increased the abundance of total and $\mathrm{mTOR}^{\mathrm{Ser} 2448}$ (Figure 1) and the abundance of complexed 4EBP1:eIF4E compared with control cows (Figure 2). No change in the abundance of total $4 \mathrm{EBP} 1,4 \mathrm{EBP} 1^{\operatorname{Ser} 65}$, total $\mathrm{p} 70 /$ $\mathrm{p} 85^{\mathrm{S} 6 \mathrm{~K}}$, and $\mathrm{p} 70^{\mathrm{S} 6 \mathrm{~K}}$ Thre $389 / \mathrm{p} 85^{\mathrm{S} 6 \mathrm{~K}}$ Thre412 (Figure 1) was observed between treatment groups. No change in relative activation was observed for any of the mTOR pathway proteins measured between treatment groups. 
Table 2. Mammary gland weight, total parenchymal content, and parenchymal ratio in cows treated with growth hormone $(\mathrm{GH})$ or untreated $(\text { control })^{1}$

\begin{tabular}{lcccc}
\hline Measurement & $\begin{array}{c}\mathrm{GH} \\
(\mathrm{n}=4)\end{array}$ & $\begin{array}{c}\text { Control } \\
(\mathrm{n}=4)\end{array}$ & SEM & $P$-value \\
\hline Parenchymal weight, $\mathrm{g}$ & 9,336 & 7,000 & 472 & 0.03 \\
Total parenchymal content, mg & & & & \\
DNA & 17.8 & 16.5 & 1.9 & 0.68 \\
RNA & 35.3 & 26.6 & 2.8 & 0.10 \\
Protein & 806 & 601 & 52 & 0.06 \\
Parenchymal concentration, mg/g & 1.9 & 2.4 & 0.1 & 0.09 \\
DNA & 3.8 & 3.9 & 0.4 & 0.91 \\
RNA & 86.8 & 85.6 & 6.8 & 0.91 \\
Protein & & & & \\
Parenchymal ratio & 2.13 & 1.63 & 0.29 & 0.32 \\
RNA:DNA & 47.1 & 36.1 & 4.0 & 0.14 \\
Protein:DNA & 24.0 & 22.8 & 2.5 & 0.76 \\
Protein:RNA & &
\end{tabular}

${ }^{1}$ Each control and GH value (excluding mammary gland weight) represents the average of 3 independent extractions and their pooled SEM; $P \leq 0.05=$ significant; $P \leq 0.15=$ trend.

\section{Effect of GH Treatment on MAPK Signaling Pathway}

The MAPK pathways regulate proliferation and differentiation, in part by controlling the protein translation machinery (Ueda et al., 2004). They are activated by mitogenic stimuli such as growth factors and cytokines, including IGF1. The abundance of MAPK pathway proteins total eIF4E, eIF4E $\mathrm{E}^{\mathrm{Ser} 209}$, total MKNK1, and MKNK1 ${ }^{\text {Thre197/202 }}$, and total RPS6KA1 (Figure 3) and the formation of the eIF4E:eIF4G complex (Figure 2 ) were increased in GH-treated compared with control cows. No change in relative activation was observed for any of the MAPK pathway proteins measured between treatment groups.

\section{Effect of GH Treatment on Mammary Gland Gene Expression}

The mRNA abundance of IGFBP3, IGFBP 5, $18 S$ $r R N A$, and RPS6KA1 were increased by 1.4-, 1.6-, 1.8-, and 1.3-fold, respectively, in mammary tissue

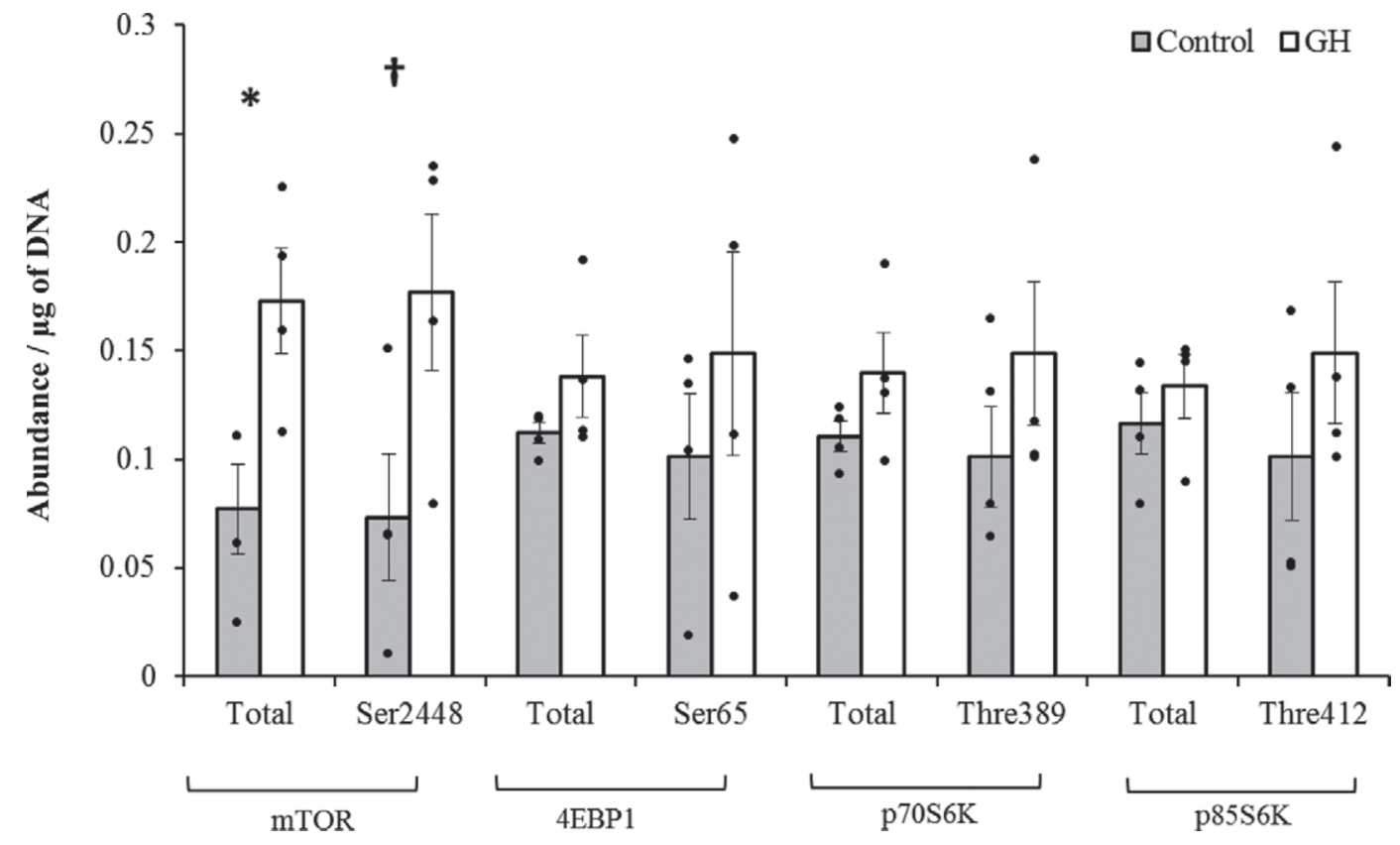

Figure 1. Growth hormone (GH) treatment increased the abundance of total and Ser2448 phosphorylated mechanistic target of rapamycin (mTOR) compared with controls. No treatment effect was observed for $4 \mathrm{EBP} 1,4 \mathrm{EBP} 1^{\mathrm{Ser} 65}, \mathrm{p} 70 \mathrm{~S} 6 \mathrm{~K}, \mathrm{p} 70^{56 \mathrm{~K}} \mathrm{Thre} 389$, p85S6K, or p85 $85^{\mathrm{S6}}$ Thre 412 . The figure shows values for each animal measured $\left(\bullet, \mathrm{n}=4\right.$ /treatment), the mean of those values (bars) \pm standard errors (lines); ${ }^{*} P \leq 0.05$, $\dagger P \leq 0.15$. 


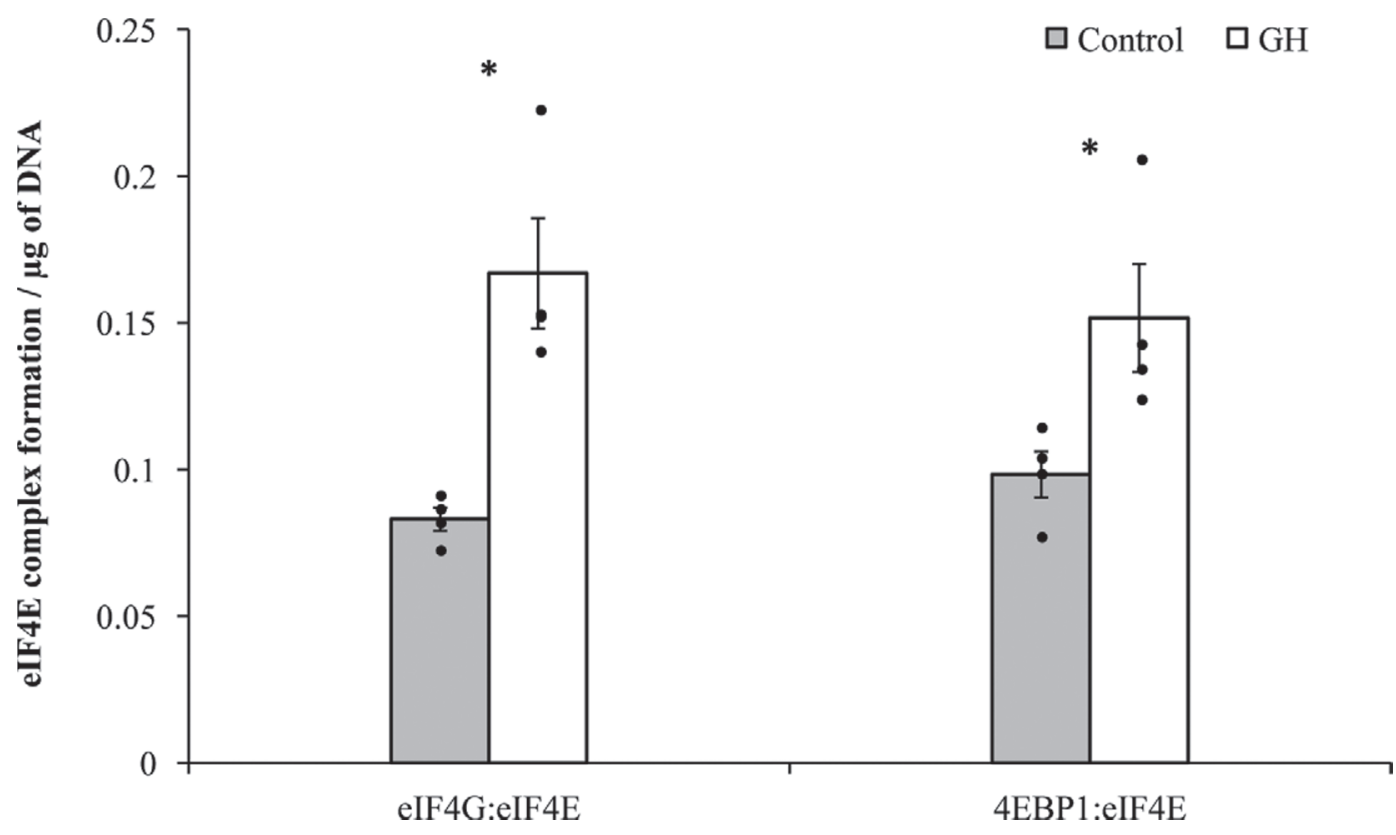

Figure 2. Growth hormone $(\mathrm{GH})$ treatment increased the association of total 4EBP1 and eIF4G with total eIF4E. The figure shows values for each animal measured $\left(\bullet, \mathrm{n}=4\right.$ /treatment), the mean of those values (bars) \pm standard errors (lines); ${ }^{*} P \leq 0.05$.

of GH animals compared with controls. The mRNA abundance of $I G F 1 R$ decreased by 1.3 -fold and that of IGF1 remained unchanged in the mammary tissue of cows treated with GH compared with controls (Figure 4).

\section{Effect of GH Treatment on elF4E-Mediated Nucleocytoplasmic Export of mRNA}

The growth-promoting IGFBP3 and RPS6KA1 and the milk proteins $\alpha_{S 1}$-casein, $\alpha_{S 2}$-casein, and $\beta$-casein

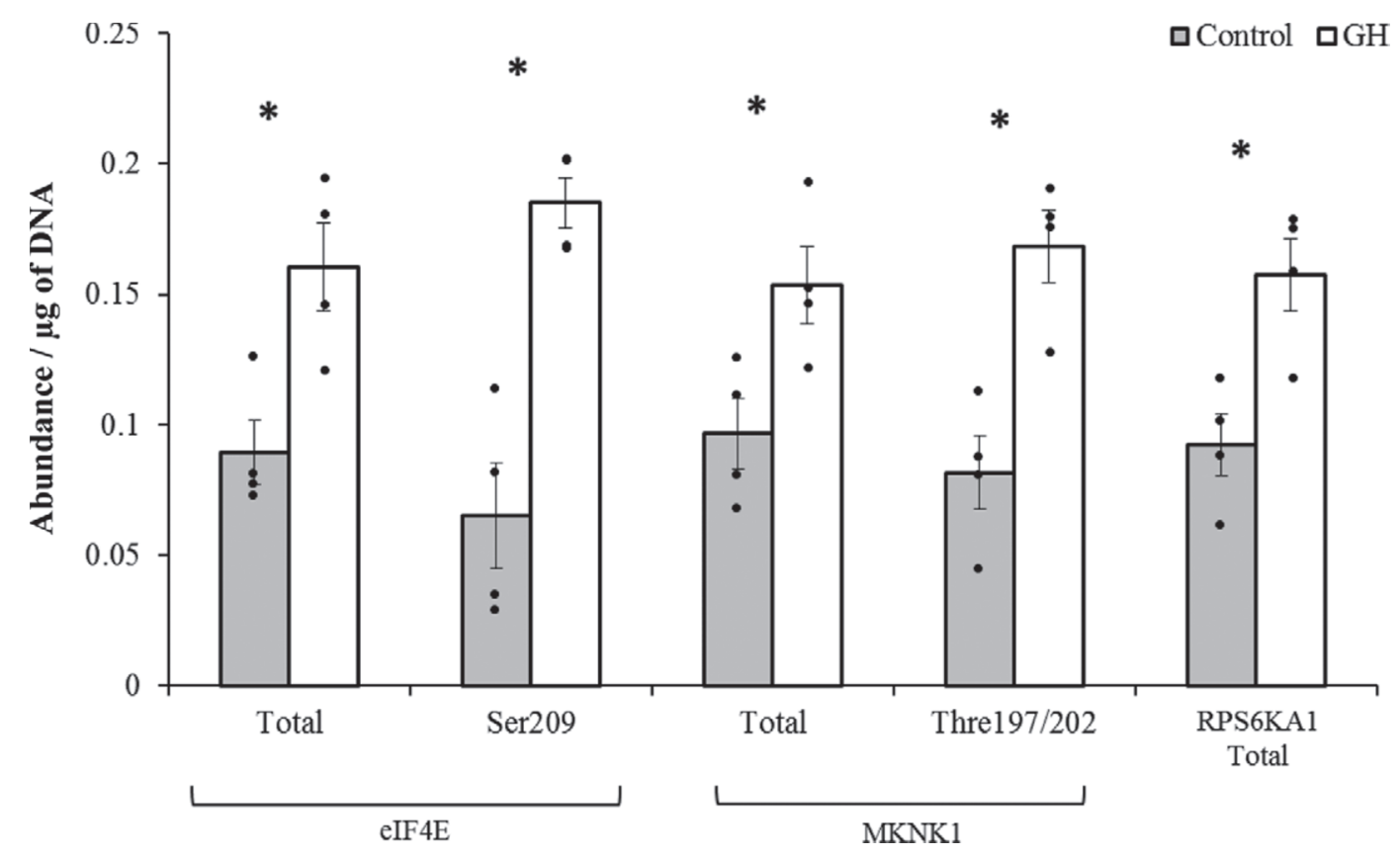

Figure 3. Growth hormone $(\mathrm{GH})$ treatment increased the abundance of MAPK signaling proteins eukaryotic initiation factor 4E (eIF4E), eIF4E $\mathrm{E}^{\text {Ser209 }}$, MKNK1, MKNK1 ${ }^{\text {Thre197/202 }}$ and RPS6KA1. The figure shows values for each animal measured $(\bullet, \mathrm{n}=4 /$ treatment $)$, the mean of those values (bars) \pm standard errors (lines); $* P \leq 0.05$. 


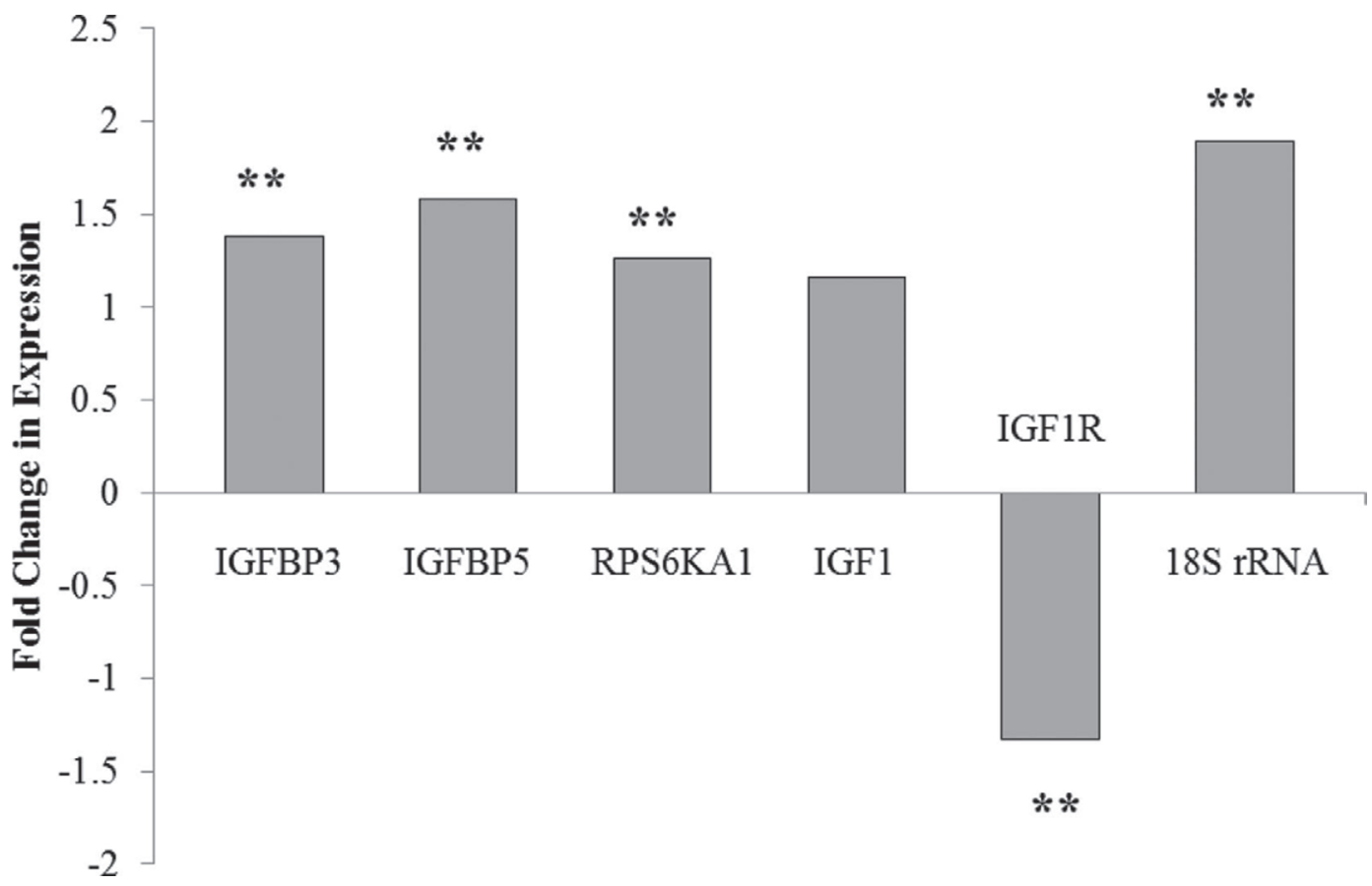

Figure 4. Growth hormone (GH) treatment increased the expression of ribosomal RNA gene $18 S$ and the IGF binding protein $(I G F B P) 3$ and IGFBP5 and decreased expression of the IGF1 receptor $(I G F 1 R)$. The mitogen-activated protein kinase (MAPK) signaling gene ribosomal protein S6 kinase, $90 \mathrm{kDa}$, polypeptide 1 (RPS6KA1) was increased, whereas MAPK and Src homology 2 domain containing 1 (SHC1) had the most stable expression of all the genes analyzed and were used as reference genes. The figure shows the fold change in gene expression in GH animals compared with control animals $\left(\mathrm{n}=4\right.$ /treatment); ${ }^{* *} P \leq 0.01$.

were shown to contain putative 4E-SE, linking their increased expression in mammary glands of $\mathrm{GH}$ cows to the increased abundance of eIF4E and eIF4E $\mathrm{E}^{\text {Ser209 }}$ (Table 3). Pro-apoptosis marker IGFBP5 and milk protein $\kappa$-casein and $\alpha$-lactalbumin mRNA were elevated in mammary glands of GH compared with control cows, but contained no $4 \mathrm{E}-\mathrm{SE}$, indicating that their export is driven by an eIF4E-independent mechanism.

\section{DISCUSSION}

This study provides new knowledge of potential molecular mechanisms regulating milk protein synthesis in the mammary gland of lactating dairy cows treated with GH. We postulate that in response to $\mathrm{GH}$, the IGF1-IGF1R-MAPK signaling cascade regulates eIF4E-mediated nucleocytoplasmic export and translation of mRNA, whereas an as yet unidentified signaling cascade mediated by mTOR controls cell renewal, cell turnover, and rRNA transcription.

\section{GH Treatment Increases Mammary Gland Protein Synthetic Capacity}

In mammalian cells, the most abundant RNA species is rRNA, accounting for $>80 \%$ of the total cellular
RNA content (Iadevaia et al., 2012). Three subspecies of RNA exist: $5 \mathrm{~S}, 18 \mathrm{~S}$, and $28 \mathrm{~S}$, which are used by cells to manufacture ribosomes, the factories used to translate mRNA into protein. In this study, we demonstrated that GH treatment potentially increased the protein synthetic capacity of the lactating mammary gland by increasing the abundance of $18 S$ rRNA mRNA, total parenchymal RNA, and by association total parenchymal rRNA. We observed no effect on parenchymal cell number, consistent with previous cow and goat lactation studies, which showed that GH does not exert its effect on the mammary gland by increasing secretory cell number, but rather by increasing cellular hypertrophy (Capuco et al., 2001; Boutinaud et al., 2003).

\section{Elevated Total and Activated mTOR Abundance Is Associated with Increased Mammary Gland Protein Synthetic Capacity}

The observed increase in total parenchymal RNA was associated with an increase in total parenchymal protein, indicating that increased protein synthesis occurs in response to GH treatment. The regulation of protein synthesis is a highly coordinated and intricately linked 3-step process involving the expression and nucleocytoplasmic export of specific mRNA and their 


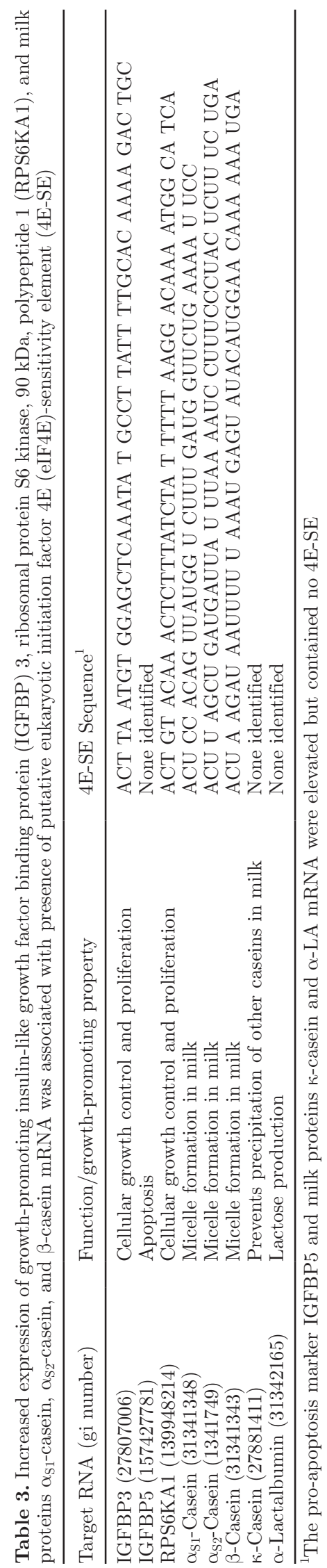

translation into protein by ribosomes. Ribosomal RNA transcription (Iadevaia et al., 2012) and mRNA nucleocytoplasmic export and translation (Ma et al., 2008) in mammalian cells are regulated by mTOR signaling. In this study, the abundance of total and $\mathrm{mTOR}^{\mathrm{Ser2448}}$ was increased in response to GH compared with controls, indicating that the mTOR pathway plays a potential role in mediating the effect of $\mathrm{GH}$ in the lactating mammary gland.

The nucleocytoplasmic export of specific mRNA and their translation into protein is regulated by the mTOR pathway and mediated by several downstream factors common to each process: 4EBP1, p $70^{\mathrm{S} 6 \mathrm{~K}}$ and p85 ${ }^{\mathrm{S} 6 \mathrm{~K}}$ (Ma et al., 2008; Rong et al., 2008). The 4EBP1 protein has an estimated nuclear to cytoplasmic ratio of 30:70, where its principal role in both sub-cellular compartments is to bind eIF4E (Rong et al., 2008). Phosphorylation of 4EBP1 by mTOR at Ser65 releases eIF4E. In the nucleus, this leads to downregulation of eIF4E-mediated mRNA export, whereas in the cytoplasm, it leads to increased initiation of protein synthesis. In response to GH treatment, 4EBP1:eIF4E complex formation was increased, but no change in the abundance of total and activated 4EBP1 was observed. This result agrees with the findings of Toerien and Cant (2007), who reported increased 4EBP1:eIF4E complex in lactating dairy cows compared with nonlactating cows and concluded that this was due to the glands of lactating cows not operating at maximum capacity. Based on observations from the present study, it is more likely that in response to increasing levels of protein synthesis, secretory cells sequester more eIF4E into the nucleus via interaction with $4 \mathrm{EBP} 1$ to support elevated nucleocytoplasmic export of specific mRNA.

Regulation of protein synthesis by mTOR signaling also occurs via Thre ${ }^{389 / 412}$ phosphorylation of $\mathrm{p} 70 /$ $\mathrm{p} 85^{\mathrm{S} 6 \mathrm{~K}}$, enhancing the transcription of specific mRNA, and phosphorylation of RPS6 at Ser235/236 (Wickenden and Watson, 2010). We showed previously that GH treatment increases phosphorylation of RPS6 $6^{\mathrm{Ser} 235 / 236}$ (Hayashi et al., 2009), a well-established change associated with increased cell size (Ruvinsky et al., 2005). In this study, cell size was increased; however, the abundance of total and $\mathrm{p} 70 / \mathrm{p} 85^{\mathrm{S} 6 \mathrm{~K}} \mathrm{Thre}^{389 / 412}$ was unaffected. These results indicate that the regulation of RPS6 ${ }^{\text {Ser235/236 }}$ phosphorylation, and potentially cell size, occurred via an mTOR-independent mechanism. The phosphorylation of RPS6 ${ }^{\mathrm{Ser} 235 / 236}$ can also be regulated by RPS6KA1, a downstream target of the MAPK signaling cascade (Roux et al., 2007). We observed that the abundance of RPS6KA1 increased in response to GH treatment, suggesting that MAPK signaling also controls RPS6 $6^{\mathrm{Ser} 235 / 236}$ phosphorylation. 
The relative abundance of phosphorylated $\mathrm{mTOR}^{\text {Ser2448 }}, 4 \mathrm{EBP} 1^{\mathrm{Ser} 65}$, or $\mathrm{p} 70 / \mathrm{p}^{55^{\mathrm{S} 6 \mathrm{~K}}} \mathrm{Thre}^{389 / 412}$ to total abundance (activation) did not change in $\mathrm{GH}$ compared with control cows, in contrast to other ruminant lactation studies in which elevated protein synthesis was associated with increased activation of signaling components upstream and downstream of the mTOR pathway (Toerien and Cant, 2007; Hayashi et al., 2009; Burgos et al., 2010). We postulate, based on the results from this study, that in response to GH treatment, the protein synthetic capacity of the mammary gland is increased via mTOR regulation of factors that control rRNA transcription, consistent with the model of chronic increased protein synthesis proposed by Wang and Proud (2006).

\section{Changes in MAPK Signaling Are Associated with Increased Nucleocytoplasmic mRNA Export and Translation}

Located at the $5^{\prime}$-end of an mRNA molecule is the m7G cap, a structure required for the mRNA's cytoplasmic translation into protein (Culjkovic et al., 2006). In the nucleus, a subset of mRNA molecules use the $5^{\prime}-\mathrm{m} 7 \mathrm{G}$ cap and an extra stem-loop pair in the $3^{\prime}$ UTR known as the $4 \mathrm{E}-\mathrm{SE}$ to mediate their export to the cytoplasm (Culjkovic et al., 2006). Each process is mediated by the protein eIF4E, which is bound to the $5^{\prime}-\mathrm{m} 7 \mathrm{G}$ cap. Cytoplasmic eIF4E initiates mRNA translation by binding eIF4G and recruiting the multiprotein eIF4F complex to the $5^{\prime}$-m7G cap (Avdulov et al., 2004). We observed that formation of the eIF4E:eIF4G complex was increased in response to GH, suggesting that the observed increase in total parenchymal protein could be a function of elevated mRNA translation. Nuclear eIF4E binds both the $5^{\prime}$-m7G cap and 4E-SE to mediate the export specific mRNA molecules involved in cellular growth and proliferation (Culjkovic et al., 2005). Results from this study using a PatSearch analysis of genes known to be upregulated in response to $\mathrm{GH}$ showed growth-promoting IGFBP3 and RPS6KA1 and the milk proteins $\alpha_{\mathrm{S1}^{-}}$-casein, $\alpha_{\mathrm{S} 2^{-}}$casein, and $\beta$-casein mRNA, which contained putative 4E-SE. Therefore, nuclear eIF4E may play a role in mediating the export of mRNA molecules that encode proteins used for cell survival and milk protein synthesis in response to GH. This is the first study to show that milk protein mRNA molecules contain $4 \mathrm{E}-\mathrm{SE}$ and that their presence is associated with increased expression in the lactating mammary gland of the GH-supplemented cow.

The abundance of total and eIF $4 \mathrm{E}^{\mathrm{Ser} 209}$ and the eIF4E:eIF4G complex increased in response to GH. These results suggest that rather than utilizing the mTOR signaling pathway to phosphorylate $4 \mathrm{EBP} 1^{\text {Ser65 }}$ and relieve the repression of protein synthesis, secretory cells in the mammary gland increase eIF4E production. This method of elevating protein synthesis has been well characterized in mammalian cells undergoing oncogenic transformation (De Benedetti and Graff, 2004). Evidence also shows that mammalian cells may increase eIF4E production in response to increased expression of mRNA containing 4E-SE to mediate their export from the nucleus (Culjkovic et al., 2005). The role of eIF $4 \mathrm{E}^{\mathrm{Ser} 209}$ is still under investigation, but its elevation in response to GH fits with the 2 mechanisms proposed in the literature. First, Zuberek et al. (2003), using intein-mediated protein ligation, generated pure eIF4E selectively phosphorylated at Ser 209. Results from that study showed that eIF4E $\mathrm{E}^{\mathrm{Ser} 209}$ has less affinity for $5^{\prime}-\mathrm{m} 7 \mathrm{G}$. Those authors proposed that the reduced interaction allowed eIF4E to use a "skipping mechanism." In this model, eIF4E recruits an eIF4F complex to the $5^{\prime}-\mathrm{m} 7 \mathrm{G}$. Once translation has begun, eIF4E can dissociate from the complex and skip to the $5^{\prime}$-m7G of another mRNA molecule, recruiting another eIF4F complex, leading to increased protein translation initiation. Second, and in agreement, Topisirovic et al. (2004) reported that nuclear eIF4E $\mathrm{E}^{\text {Ser209 }}$ has less affinity for $5^{\prime}-\mathrm{m} 7 \mathrm{G}$, and proposed that this feature aids in eIF4E-mediated transport of mRNA from the nucleus of NIH3T3 cells. Interestingly, eIF4E:eIF4G complex formation and elevation of eIF4 $\mathrm{E}^{\mathrm{Ser} 209}$ phosphorylation are controlled by MKNK1, a kinase in the MAPK pathway (Ueda et al., 2004). We observed that the abundance of total and MKNK1 $1^{\text {Thre197/202 }}$ was increased in response to $\mathrm{GH}$, providing further support to our hypothesis that elevated eIF4E $\mathrm{E}^{\text {Ser209 }}$ and eIF4E:eIF4G formation occur via MAPK signaling in response to $\mathrm{GH}$ treatment.

\section{Changes in IGF1-IGF1R Signaling Potentially Regulate the MAPK and mTORC1 Pathways}

Previously, researchers reported that circulating levels of IGF1 increase in response to GH treatment (Prosser et al., 1989; Hayashi et al., 2009), which suggests that GH may exert its influence on the mammary gland by utilizing the IGF1-IGFR signaling cascade. The IGF1R auto-phosphorylates and activates downstream signaling pathways in response to IGF1 binding (Fleming et al., 2005). The 2 classical signaling pathways activated by IGF1 are the phosphatidylinositol-3 kinase (PI3K) and MAPK pathways. The IGF1-IGFRMAPK signaling cascade regulates nucleocytoplasmic export and translation initiation of mRNA, whereas the IGF1-IGFR-PI3K-mTOR signaling cascade regulates IGFBP3 and IGFBP5 expression (Fleming et al., 2005). Increased IGFBP3 expression aids cell survival and proliferation, whereas increased IGFBP5 has been 


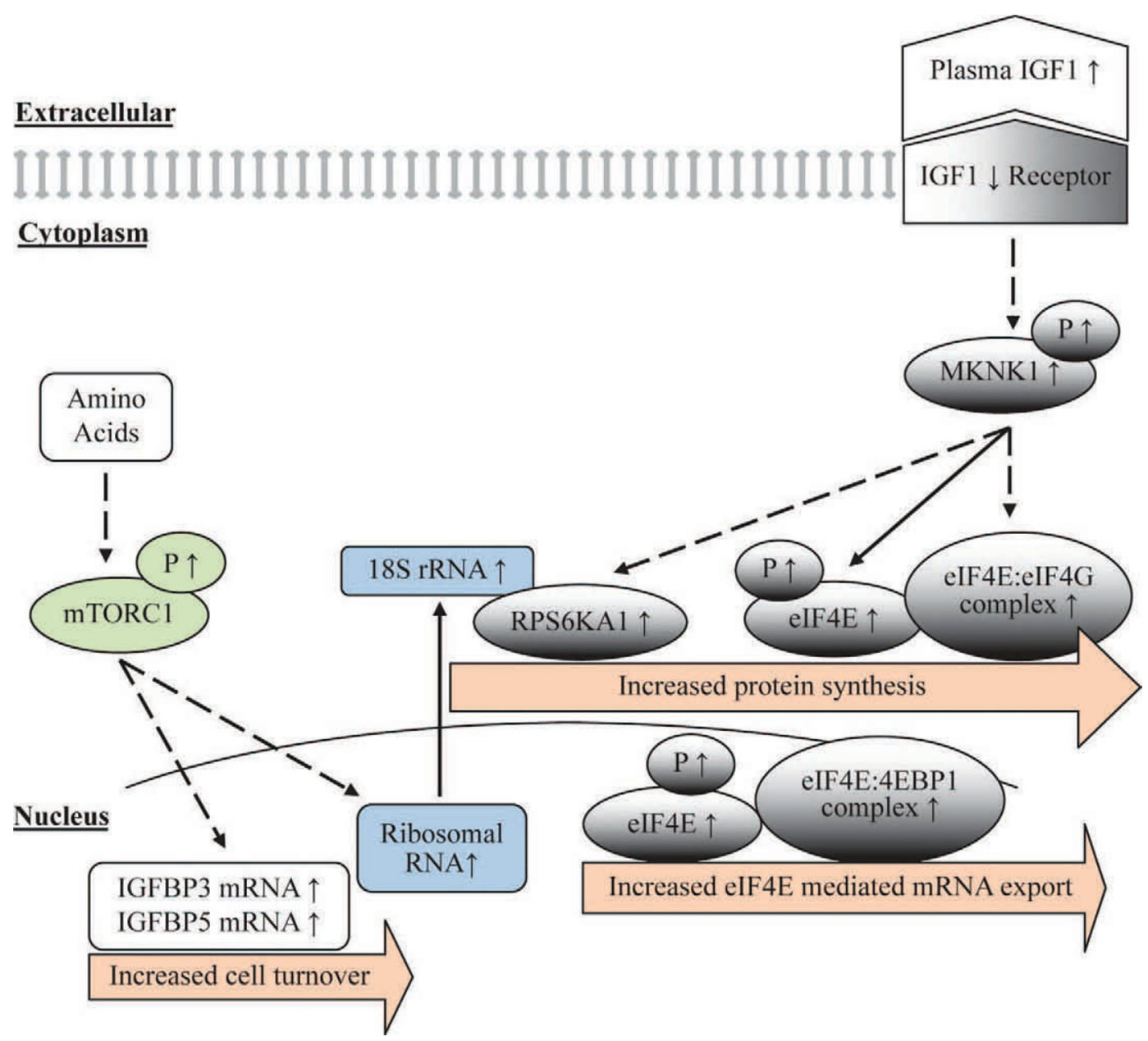

Figure 5. Proposed model of the results presented in this study. Solid arrows represent data with direct links to results generated in this study, whereas dashed arrows represent data with indirect links supported by the literature. mTORC1 = mechanistic (mammalian) target of rapamycin complex 1; RPS6KA1 = ribosomal protein S6 kinase, $90 \mathrm{kDa}$, polypeptide 1; IGFBP3 and IGFBP5 = IGF binding protein 3 and 5 ; SHC1 = Src homology 2 domain containing 1; MAPK = mitogen-activated protein kinase; MKNK1 = MAP kinase-interacting serine/threonineprotein kinase 1 ; eIF4E = eukaryotic initiation factor $4 \mathrm{E}$; eIF4G = eukaryotic initiation factor 4G; 4EBP1 = eukaryotic initiation factor $4 \mathrm{E}$ binding protein $1 ; \mathrm{P}=$ phosphorylated form. Color version available in the online PDF.

linked to apoptosis and remodeling of the mammary gland (Flint et al., 2000). In vitro studies with the bovine mammary epithelial cell line MAC-T show that IGF1 stimulates mTOR pathway activation and protein synthesis (Burgos and Cant, 2010). We observed that expression of both IGFBP3 and IGFBP5 were increased in the mammary gland of GH-treated cows, suggesting that mTOR signaling may play a role in maintaining cell number in the mammary gland through increased cell turnover and renewal (Capuco et al., 2001). This agrees with our biochemical indices results, which showed that cell number was unaffected by GH treatment. Gene expression analysis also showed that IG1R mRNA was decreased, whereas autocrine expression of IGF1 was unchanged. This may indicate that IGF1 signaling did not occur through an autocrine mechanism but rather through a para- or endocrine mechanism. Expression of IGF1R decreased when the levels of IGF1 increased, an action that stimulated apoptosis and was associated with increased IGFBP3 expression (Chi et al., 2000). It is important to note that previous reports state that activation of the IGF1-IGFR-MAPK signaling cascade reduces the expression of IGFBP3 and IGFBP5 (Fleming et al., 2007). This reduction could indicate a potential uncoupling of mTORC1 and MAPK signaling via regulation from another pathway and warrants further investigation.

The findings from this study indicate that increased milk protein production in response to $\mathrm{GH}$ is potentially mediated by mTORC1 and MAPK signaling, stimulated by IGF1-IGF1R activation (Figure 5). Increased abundance of total and $\mathrm{mTOR}^{\mathrm{Ser} 248}$ is associ- 
ated with elevated total parenchymal RNA, an indicator of protein synthetic capacity. Increased abundance of total and $\mathrm{mTOR}^{\mathrm{Ser} 2448}$ is also linked to the maintenance of cell number (indicated by total parenchymal DNA content), potentially operating via regulation of increased expression of IGFBP3 and IGFBP5, which are measures of cell renewal and turnover. Increased abundance of total and phosphorylated components of MAPK signaling pathway are associated with elevated eIF4E-mediated nucleocytoplasmic mRNA export and the initiation of mRNA translation in the cytoplasm. Decreased expression of IGF1R indicates increased levels of circulating IGF1 are directly signaling to the lactating gland through the MAPK and mTORC1 pathways. Although the MAPK pathway principally responds to mitogens and hormones, mTORC1 has a far wider range of signaling inputs, including energy, hypoxia, and amino acids (Wang and Proud, 2006). Further research will be required to determine the potential role that IGF1-IGF1R activation plays in regulating mTORC1 and MAPK signaling and to identify if other signaling pathways stimulate mTORC1 and MAPK.

\section{ACKNOWLEDGMENTS}

The authors gratefully acknowledge Nicole Roy, Warren McNabb, Bruce Sinclair, Matt Deighton, Kate Broadley, Jason Peters, Peter Schreurs, Andrea Death, Clare Reynolds, Ann-Charlotte Pupin, and Jenifer Lane (all of AgResearch Grasslands, Palmerston North, New Zealand) for assistance with the animal experiment. We also acknowledge funding from the Ministry for Science and Innovation and the AgResearch Capability Fund (Maori PhD fellowship for Q. Sciascia). The animal trial, from which the tissues used in this experiment were derived, was conducted as part of a Joint Venture between AgResearch Limited (New Zealand) and Primary Industries Research Victoria (Australia).

\section{REFERENCES}

Andersen, C. L., J. L. Jensen, and T. F. Orntoft. 2004. Normalization of real-time quantitative reverse transcription-PCR data: A model-based variance estimation approach to identify genes suited for normalization, applied to bladder and colon cancer data sets. Cancer Res. 64:5245-5250.

Avdulov, S., S. Li, V. Michalek, D. Burrichter, M. Peterson, D. M. Perlman, J. C. Manivel, N. Sonenberg, D. Yee, P. B. Bitterman, and V. A. Polunovsky. 2004. Activation of translation complex eIF4F is essential for the genesis and maintenance of the malignant phenotype in human mammary epithelial cells. Cancer Cell 5:553-563.

Boutinaud, M., C. Rousseau, D. H. Keisler, and H. Jammes. 2003. Growth hormone and milking frequency act differently on goat mammary gland in late lactation. J. Dairy Sci. 86:509-520.

Bradford, M. M. 1976. A rapid and sensitive method for the quantitation of microgram quantities of protein utilizing the principle of protein-dye binding. Anal. Biochem. 72:248-254.
Brisken, C., and B. O'Malley. 2010. Hormone action in the mammary gland. Cold Spring Harb. Perspect. Biol. 4:a00317.

Burgos, S. A., and J. P. Cant. 2010. IGF-1 stimulates protein synthesis by enhanced signaling through mTORC1 in bovine mammary epithelial cells. Domest. Anim. Endocrinol. 38:211-221.

Burgos, S. A., M. Dai, and J. P. Cant. 2010. Nutrient availability and lactogenic hormones regulate mammary protein synthesis through the mammalian target of rapamycin signaling pathway. J. Dairy Sci. 93:153-161.

Bustin, S. A., V. Benes, J. A. Garson, J. Hellemans, J. Huggett, M. Kubista, R. Mueller, T. Nolan, M. W. Pfaffl, G. L. Shipley, J. Vandesompele, and C. T. Wittwer. 2009. The MIQE guidelines: Minimum information for publication of quantitative real-time PCR experiments. Clin. Chem. 55:611-622.

Capuco, A. V., D. L. Wood, R. Baldwin, K. McLeod, and M. J. Paape. 2001. Mammary cell number, proliferation, and apoptosis during a bovine lactation: Relation to milk production and effect of bST. J. Dairy Sci. 84:2177-2187.

Chi, M. M., A. L. Schlein, and K. H. Moley. 2000. High insulin-like growth factor 1 (IGF-1) and insulin concentrations trigger apoptosis in the mouse blastocyst via down-regulation of the IGF-1 receptor. Endocrinology 141:4784-4792.

Culjkovic, B., K. Tan, S. Orolicki, A. Amri, S. Meloche, and K. L. Borden. 2008. The eIF4E RNA regulon promotes the Akt signaling pathway. J. Cell Biol. 181:51-63.

Culjkovic, B., I. Topisirovic, L. Skrabanek, M. Ruiz-Gutierrez, and K. L. Borden. 2005. eIF4E promotes nuclear export of cyclin D1 mRNAs via an element in the 3' UTR. J. Cell Biol. 169:245-256.

Culjkovic, B., I. Topisirovic, L. Skrabanek, M. Ruiz-Gutierrez, and K. L. Borden. 2006. eIF4E is a central node of an RNA regulon that governs cellular proliferation. J. Cell Biol. 175:415-426.

Davis, S. R., R. J. Collier, J. P. McNamara, H. H. Head, and W. Sussman. 1988. Effects of thyroxine and growth hormone treatment of dairy cows on milk yield, cardiac output and mammary blood flow. J. Anim. Sci. 66:70-79.

De Benedetti, A., and J. R. Graff. 2004. eIF-4E expression and its role in malignancies and metastases. Oncogene 23:3189-3199.

Fleming, J. M., J. A. Brandimarto, and W. S. Cohick. 2007. The mitogen-activated protein kinase pathway tonically inhibits both basal and IGF-I-stimulated IGF-binding protein-5 production in mammary epithelial cells. J. Endocrinol. 194:349-359.

Fleming, J. M., B. J. Leibowitz, D. E. Kerr, and W. S. Cohick. 2005. IGF-I differentially regulates IGF-binding protein expression in primary mammary fibroblasts and epithelial cells. J. Endocrinol. 186:165-178.

Flint, D. J., E. Tonner, and G. J. Allan. 2000. Insulin-like growth factor binding proteins: IGF-dependent and -independent effects in the mammary gland. J. Mammary Gland Biol. Neoplasia 5:65-73.

Gingras, A. C., B. Raught, S. P. Gygi, A. Niedzwiecka, M. Miron, S. K. Burley, R. D. Polakiewicz, A. Wyslouch-Cieszynska, R. Aebersold, and N. Sonenberg. 2001. Hierarchical phosphorylation of the translation inhibitor 4E-BP1. Genes Dev. 15:2852-2864.

Hayashi, A. A., K. Nones, N. C. Roy, W. C. McNabb, D. S. Mackenzie, D. Pacheco, and S. McCoard. 2009. Initiation and elongation steps of mRNA translation are involved in the increase in milk protein yield caused by growth hormone administration during lactation. J. Dairy Sci. 92:1889-1899.

Iadevaia, V., Z. Zhang, E. Jan, and C. G. Proud. 2012. mTOR signaling regulates the processing of pre-rRNA in human cells. Nucleic Acids Res. 40:2527-2539.

Jacinto, E., R. Loewith, A. Schmidt, S. Lin, M. A. Ruegg, A. Hall, and M. N. Hall. 2004. Mammalian TOR complex 2 controls the actin cytoskeleton and is rapamycin insensitive. Nat. Cell Biol. 6:1122-1128

Johnson, T. L., B. A. Fujimoto, R. Jimenez-Flores, and D. G. Peterson. 2010. Growth hormone alters lipid composition and increases the abundance of casein and lactalbumin mRNA in the MAC-T cell line. J. Dairy Res. 77:199-204.

Kantidakis, T., B. A. Ramsbottom, J. L. Birch, S. N. Dowding, and R. J. White. 2010. mTOR associates with TFIIIC, is found at tRNA 
and 5S rRNA genes, and targets their repressor Maf1. Proc. Natl. Acad. Sci. USA 107:11823-11828.

Ma, X. M., S. O. Yoon, C. J. Richardson, K. Julich, and J. Blenis. 2008. SKAR links pre-mRNA splicing to mTOR/S6K1-mediated enhanced translation efficiency of spliced mRNAs. Cell 133:303313.

McDowell, G. H., J. M. Gooden, D. Leenanuruksa, M. Jois, and A. W. English. 1987. Effects of exogenous growth hormone on milk production and nutrient uptake by muscle and mammary tissues of dairy cows in mid-lactation. Aust. J. Biol. Sci. 40:295-306.

Mepham, T. B., S. E. Lawrence, A. R. Peters, and I. C. Hart. 1984 Effects of exogenous growth hormone on mammary function in lactating goats. Horm. Metab. Res. 16:248-253.

Pfaffl, M. W., T. M. Georgieva, I. P. Georgiev, E. Ontsouka, M. Hageleit, and J. W. Blum. 2002a. Real-time RT-PCR quantification of insulin-like growth factor (IGF)-1, IGF-1 receptor, IGF-2, IGF-2 receptor, insulin receptor, growth hormone receptor, IGFbinding proteins 1,2 and 3 in the bovine species. Domest. Anim. Endocrinol. 22:91-102.

Pfaffl, M. W., G. W. Horgan, and L. Dempfle. 2002b. Relative expression software tool (REST) for group-wise comparison and statistical analysis of relative expression results in real-time PCR. Nucleic Acids Res. 30:e36.

Prosser, C. G., I. R. Fleet, and A. N. Corps. 1989. Increased secretion of insulin-like growth factor I into milk of cows treated with recombinantly derived bovine growth hormone. J. Dairy Res. 56:17-26.

Ramakers, C., J. M. Ruijter, R. H. Deprez, and A. F. Moorman. 2003 Assumption-free analysis of quantitative real-time polymerase chain reaction (PCR) data. Neurosci. Lett. 339:62-66.

Rong, L., M. Livingstone, R. Sukarieh, E. Petroulakis, A. C. Gingras, K. Crosby, B. Smith, R. D. Polakiewicz, J. Pelletier, M. A. Ferraiuolo, and N. Sonenberg. 2008. Control of eIF4E cellular localization by eIF4E-binding proteins, 4E-BPs. RNA 14:1318-1327.

Roux, P. P., D. Shahbazian, H. Vu, M. K. Holz, M. S. Cohen, J. Taunton, N. Sonenberg, and J. Blenis. 2007. RAS/ERK signaling promotes site-specific ribosomal protein $\mathrm{S} 6$ phosphorylation via RSK and stimulates cap-dependent translation. J. Biol. Chem. 282:14056-14064.
Ruvinsky, I., and O. Meyuhas. 2006. Ribosomal protein S6 phosphorylation: from protein synthesis to cell size. Trends Biochem. Sci. $31: 342-348$.

Ruvinsky, I., N. Sharon, T. Lerer, H. Cohen, M. Stolovich-Rain, T. Nir, Y. Dor, P. Zisman, and O. Meyuhas. 2005. Ribosomal protein S6 phosphorylation is a determinant of cell size and glucose homeostasis. Genes Dev. 19:2199-2211.

Sakamoto, K., T. Yano, T. Kobayashi, A. Hagino, H. Aso, and Y. Obara. 2007. Growth hormone suppresses the expression of IGFBP-5, and promotes the IGF-I-induced phosphorylation of Akt in bovine mammary epithelial cells. Domest. Anim. Endocrinol. 32:260272 .

Schmelzle, T., and M. N. Hall. 2000. TOR, a central controller of cell growth. Cell 103:253-262.

Toerien, C. A., and J. P. Cant. 2007. Abundance and phosphorylation state of translation initiation factors in mammary glands of lactating and nonlactating dairy cows. J. Dairy Sci. 90:2726-2734.

Topisirovic, I., M. Ruiz-Gutierrez, and K. L. Borden. 2004. Phosphorylation of the eukaryotic translation initiation factor eIF4E contributes to its transformation and mRNA transport activities. Cancer Res. 64:8639-8642.

Ueda, T., R. Watanabe-Fukunaga, H. Fukuyama, S. Nagata, and R. Fukunaga. 2004. Mnk2 and Mnk1 are essential for constitutive and inducible phosphorylation of eukaryotic initiation factor $4 \mathrm{E}$ but not for cell growth or development. Mol. Cell. Biol. 24:6539-6549.

Wang, X., and C. G. Proud. 2006. The mTOR pathway in the control of protein synthesis. Physiology (Bethesda) 21:362-369.

Wickenden, J. A., and C. J. Watson. 2010. Key signalling nodes in mammary gland development and cancer. Signalling downstream of PI3 kinase in mammary epithelium: A play in 3 Akts. Breast Cancer Res. 12:202.

Zuberek, J., A. Wyslouch-Cieszynska, A. Niedzwiecka, M. Dadlez, J. Stepinski, W. Augustyniak, A. C. Gingras, Z. Zhang, S. K. Burley, N. Sonenberg, R. Stolarski, and E. Darzynkiewicz. 2003. Phosphorylation of eIF4E attenuates its interaction with mRNA 5' cap analogs by electrostatic repulsion: Intein-mediated protein ligation strategy to obtain phosphorylated protein. RNA 9:52-61. 